Uwe Schneidewind, Karoline Augenstein

\title{
Analyzing a transition to a sustainability-oriented science system in Germany
}

Originally published as:

Uwe Schneidewind, Karoline Augenstein (2012):

Analyzing a transition to a sustainability-oriented science system in Germany In: Environmental Innovation and Societal Transitions, 3, 16-28 
Uwe Schneidewind ${ }^{a, b,{ }^{*},}$ Karoline Augenstein ${ }^{a}$

\section{Analyzing a transition to a sustainability-oriented science system in Germany}

a Wuppertal Institute for Climate, Environment, Energy, Germany

b Schumpeter School of Business and Economics, Bergische Universität Wuppertal, Germany

* Corresponding author: Uwe Schneidewind, Wuppertal Institute for Climate, Environment, Energy, Döppersberg 19, 42103 Wuppertal, Germany

E-mail: uwe.schneidewind@wupperinst.org

Phone: +49-202-2492100

Fax: $+49-202-2492108$ 


\title{
Analyzing a transition to a sustainability-oriented science system in Germany
}

\begin{abstract}
The Multi-Level Perspective has successfully been applied to the analysis of complex sector transitions in the energy, the health or the food production sector. Is this framework also helpful to understand and give prescriptive advice for sustainability transformations within a national science system? Based on a comprehensive study of the diffusion of transdisciplinary sustainability research in Germany, this article analyzes the institutional dimension of a changing science-society relation in the German science system. It uses the Multi-Level Perspective as a fruitful heuristic in order to identify potential pathways for a broader diffusion of transdisciplinary sustainability science. The importance of niche coalitions of frontrunner universities and research institutes are highlighted.
\end{abstract}

\section{Introduction}

Sustainability challenges (such as climate change, resource scarcity, biodiversity loss) gain growing importance in modern societies. The causes as well as the solutions for these challenges are knowledge-driven: the majority of the problems are related to the high energyand resource-consumption of modern, technology-based knowledge societies. These challenges cannot be met without knowledge-driven, ecologically oriented technological solutions as well as by a better understanding of comprehensive societal and economic transitions towards a more sustainable development. However, problems related to sustainability are usually complex, ambiguous and multi-dimensionsional, thus generally precluding the existence of simple solutions. To fully capture such problems, different perspectives on problem perception and various types of knowledge need to be integrated. Above all, a new perspective on scientific knowledge in general is needed, in order to deal with such problems.

In order to fully grasp this fundamental challenge, this paper will analytically frame the development of sustainability-oriented transdisciplinary research approaches as part of an envisaged, wide-ranging transition process - where a radical niche development is in conflict with an existing institutional setting and aims at changing it.

To some extent such an application of a transition research framework is a self-application of this theoretical approach to its own institutional preconditions: Transition research itself is a specific form of transdisciplinary research. Understanding how the science system has to change, in order to foster a broader diffusion of this kind of research, is methodologically inspiring: It makes transitions scientists change agents in their own system and helps to better understand the potential of guiding principles delivered by the multi-level perspective. It provides opportunities for an educated "trial and error" (following the idea and importance of experimental settings in the transition approach) and shows how the heuristic of the multilevel perspective facilitates the identification of successful institutional strategies to change the system. A number of such strategies can be observed within the German science system. 
The following section will introduce the concept of transdisciplinary sustainability research and its institutional implications for the science system. Section 3 will then give an overview of how structural change processes are conceptualized in the literature on socio-technical transitions. In section 4, a multi-level transition framework is applied to the German science system. Based on this, the potential of various niche strategies for triggering a transition towards transdisciplinary sustainability research will be analyzed in section 5 . In the final section, the results of the multi-level analysis will be discussed and conclusions will be drawn.

\section{Transdisciplinary sustainability research as a new challenge for the science system}

New perspectives on the production of knowledge and scientific research (however, not necessarily related to sustainability) have been introduced by Gibbons and others in the debate about a mode-2-science during the 1990s: Whereas mode-1-science follows classical rules of analytical knowledge production (mainly found in the natural sciences) and "tells truth to politics", mode-2-science defines its research questions together with the relevant actors (creating "target knowledge") and incorporates the contextual knowledge of actors. In mode- 2 science, there is no absolute or ultimate knowledge, discovered and authorized by scientists; rather, knowledge is co-produced by all kinds of actors and at most points in time remains provisional and constantly developing (CASS, 1997; Gibbons et al., 1994; Kemp and Marten, 2007; Nowotny et al., 2001).

In a similar vein, the concept of transdisciplinarity calls for research that transcends disciplinary boundaries and integrates lay knowledge (see for the different types of such a knowledge integration Bergmann et al., 2010, more critical Zierhofer and Burger, 2007). Transdisciplinary research has been defined as an approach that can: "(a) grasp the complexity of problems, (b) take into account the diversity of life-world and scientific perceptions of problems, (c) link abstract and case-specific knowledge, and (d) develop knowledge and practices that promote what is perceived to be the common good" (Pohl and Hirsch Hadorn, 2007, p. 20).

With regard to sustainability problems, some scholars have advocated the development of a new field of 'sustainability science', which acknowledges the ambiguous and uncertain character of real-world problems and the need for new types of knowledge production. It includes a new role of the science system in general, the major function of which is to produce knowledge that is relevant for public actors and includes a normative and practiceoriented dimension, in order to assist societies in developing in a more sustainable way. A major difference with regard to traditional science is that solutions for sustainability problems have to be sought, often at a time where it has not yet been possible to study these problems in a sufficiently comprehensive way. Here, tensions become apparent between this problemsolving approach and the traditional process of basic research followed by applied research. Thus, sustainability science should be problem-oriented, inter- and transdisciplinary with a focus on complex system dynamics and the co-production of knowledge (Clark and Dickson, 2003; Kemp and Marten, 2007; Komiyama and Takeuchi, 2006; Waas et al., 2010; Wiek et al., 2012).

According to Scholz (2011), sustainability science is based on "disciplined interdisciplinarity in transdisciplinary processes". This is a science that incorporates disciplinary and interdisciplinary scientific knowledge with actor knowledge, in order to cope with real-world problems: "Transdisciplinary processes involve collaboration among science and society and 
emphasize (1) mutual learning, (2) joint problem definition, and (3) knowledge integration. They produce socially robust knowledge" (Scholz, 2011, p. 373). The institutional preconditions for a broad diffusion of these types of transdisciplinary processes are understudied so far (see for instance Yarime et al., 2012) and build the focus of the following analysis.

Considering the emergence of these new modes of science on the one hand, and the growing need to deal with sustainability problems on the other, it becomes apparent that a transdisciplinary approach (including and integrating also mono- and interdisciplinary work) is well-suited for sustainability research that deals with complex, ambiguous, real-world problems and aims at producing robust and practice-oriented knowledge. Thus, it is advocated here that what is needed is "transdisciplinary sustainability research".

However, transdisciplinary sustainability research is not compatible with the structures of the German (and most other) science systems. The integration of different academic disciplines and of lay knowledge represent a severe institutional challenge. The science system is characterized by a trend towards vertical differentiation in a rather competitive structure. Universities as well as individual researchers are judged based on prestige and reputation within academic disciplines and measured by rigid quality criteria. The importance of reputation and the way it can be attained "has been evident in the strong, if tacit, hierarchy of journals, in the informal ranking of departments, and in its professional institutions, in what Bourdieu, for example, would call the 'agencies of reproduction' within the profession" (Harley and Lee, 1997, p. 1436; Wagner, 2007).

So, essentially a transition of the science system towards "transdisciplinary sustainability research" is needed, which would imply severe consequences for the current institutional architecture. Transdisciplinary sustainability science requires new research methods, a suitable training of junior scientists, and specific career pathways beyond disciplinary boundaries - to name only some aspects of a science system capacity building. Most of these measures can only be delivered by universities. The fact that the institutional setting of universities has historically developed in the context of disciplinary and mode-1-researchstructures is a problem for the further development of a knowledge system suitable to the challenges of a sustainable development (Jäger, 2011; Stephens and Graham, 2010).

\section{The transition approach as a way to describe sectoral changes}

The field of transition research builds on science and technology studies, innovation systems theory as well as concepts from sociology and evolutionary economics to study fundamental and long-term change in socio-technical systems and societal or industrial sectors (for a comprehensive overview of the different approaches in transition research and their respective theoretical backgrounds, see van den Bergh et al., 2011). A transition is characterized by colluding developments and dynamics taking place in various realms of society, including for instance economic, cultural and technological change. It does not only include physical changes in infrastructures or organizations, but also a redefinition of norms and values, new perspectives on how certain problems are framed or perceived and eventually acted upon. Thus, a transition can be defined as a substantial shift in the deep and underlying structure of a system. Transitions are complex and intertwined processes that are usually not linear and not easily predictable (Kemp and Loorbach, 2006; Meadowcroft, 2009; Rotmans and Loorbach, 2010; Shove and Walker, 2007).

\subsection{A multi-level perspective}


The complexity of transition processes can be conceived of in terms of a multi-level perspective. It is argued that a transition is caused by processes across three levels landscape, regime, niche - that interact and reinforce each other. These do not refer to specific spatial or organizational locations, but rather to a more theoretical idea of levels within functional space embodying different relationships between the respective actors, different dynamics and structures (Grin, 2010; Rotmans and Loorbach, 2010).

The landscape provides a relatively stable environment characterized by large-scale developments and long-term trends, which can hardly be influenced by individuals or groups of actors. A regime is defined as a set of structure, culture and practices that is shared by a specific group of actors. The regime guides the behavior and actions of its members by shaping their perceptions of problems as well as the range of possible solutions. Overall, it conceptualizes a dynamic social structure that is firmly established because it is constantly reproduced but also leaves room for a limited degree of variance. For new rules and routines to become part of a regime, individual and social learning processes are essential and issues of (normative) power need to be considered (Shove and Walker, 2007). Niches can develop where small groups of actors engage in new practices and behave in ways that do not conform to the general regime (Geels and Schot, 2010; Kemp and Loorbach, 2006; Rotmans et al., 2001; Rotmans and Loorbach, 2010).

The insight that can be gained from adopting a multi-level perspective is that transitions should best be understood as a combined process of interlinked dynamics occurring at these different levels. Pressure for change can be exerted from two directions. It is either top-down, when developments at the macro level weaken the dominant regime structures and new approaches are sought after. Pressure can also be bottom-up, when innovations at niche-level develop rapidly and include learning processes among a relevant amount of actors. Employing a multi-level perspective puts emphasis on the complex dynamics underlying a transition and at the same time offers a way of dealing with this complexity. Even though there are no simple explanations of cause and effect, nor do predetermined transition trajectories exist that can be predicted at some point of an actual transition process, the multilevel perspective can help to explain how a combination of long-term trends at landscape level, the specific structure of a regime and concrete niche-strategies trigger change processes (Geels and Schot, 2010; Rotmans and Loorbach, 2010; Voß and Kemp, 2005).

From an epistemological point of view, the multi-level perspective faces a general challenge that it shares with other conceptual frameworks, such as Giddens' structuration theory, Luhmann's systems theory or approaches from the field of institutional economics. These types of analytical frameworks provide theoretical coherence but remain rather abstract and are difficult to operationalize empirically. Thus, the focus is on providing a powerful guiding heuristic that facilitates an understanding of overall complex system dynamics. With regard to future-oriented transition studies, a system analysis based on the multi-level perspective allows for "educated trial and error", i.e. it refrains from lapsing into naïve management optimism and rather enables a reflexive governance approach.

\subsection{Transition pathways in sectors}

A transition pathway is the most comprehensive form of conceptually capturing a transition. It considers the four phases of a transition as well as the intertwined mechanisms that form a specific transition pattern. The character of such a pattern and the way it plays out over the four phases determines a specific transition pathway (Rotmans and Loorbach, 2010). The 
concept of transition phases breaks a transition process down into four subsequent phases. First, there is a pre-development phase. At this stage, the transition is prepared by small-scale developments that take place almost unnoticed. Second, during the take-off phase these developments gain in size and scope. Third, the increasing momentum becomes visible during the acceleration phase. This is the time when considerable change occurs; learning processes and broad diffusion take place. Finally, the stabilization phase marks the end of the transition process when a new, stable state has been reached (Grin et al., 2010; Kemp and Loorbach, 2006; Rotmans and Loorbach, 2010). A transition pattern is the result of a specific combination and interplay of a number of mechanisms, such as "variation and selection, adaptation, emergence, clustering, empowering, transformation, decay and building up" (Rotmans and Loorbach, 2010, p. 135). All these mechanisms are related to the persistence or change of a regime, respectively. They originate either from top-down landscape pressure, or from bottom-up niche-level developments, such as the clustering or coordination between niches (Rotmans and Loorbach, 2010).

Specific types of transition pathways have been classified in transition literature. Pathways help explain concrete patterns of change and the way bottom-up and top-down dynamics interrelate in concrete cases. For instance, the technological substitution pathway and the realignment and de-alignment pathway both describe situations where a transition is mainly triggered by a destructive crisis at the landscape level. A new regime is then built around niche innovations that are already existing at the niche level or are chaotically beginning to develop after the old regime has crumbled, respectively (Geels and Schot, 2010). At the other end of the spectrum, transformation and reconfiguration pathways are characterized by only moderate landscape pressure. In these cases, a transition occurs where regime actors willing to adapt or improve the existing regime take up niche innovations that are premature or not too radical. Such incremental change processes may then in the long run lead to more basic changes, in the end resulting in a new and fundamentally different regime (Geels, 2006; Geels and Schot, 2010).

\section{A multi-level perspective on the German science system}

How can these pathways, originally developed in order to better describe industrial sector transitions focusing on technological niche innovations and their wider social and cultural implications, be useful for the analysis of science system transitions? It is argued here that the underlying structure and dynamics observed in these pathways can guide the study of the science system as well. Thus, this section throws a glance at the German science system from a multi-level perspective on sustainability transitions (see Fig. 1). As in other sectors, landscape-, regime- and niche-elements can be identified to describe the German science system. In this respect, the multi-level perspective is a suitable concept for characterizing the German system, as one example of a national science system.

Demographic change, new communication technologies, growing public deficits and an intensified globalization of the Higher Education Sector are relevant landscape factors. They are putting pressure on the existing regime: demanding a higher productivity (because of reduced government spending) and provoking a growing competition and differentiation between the universities. 


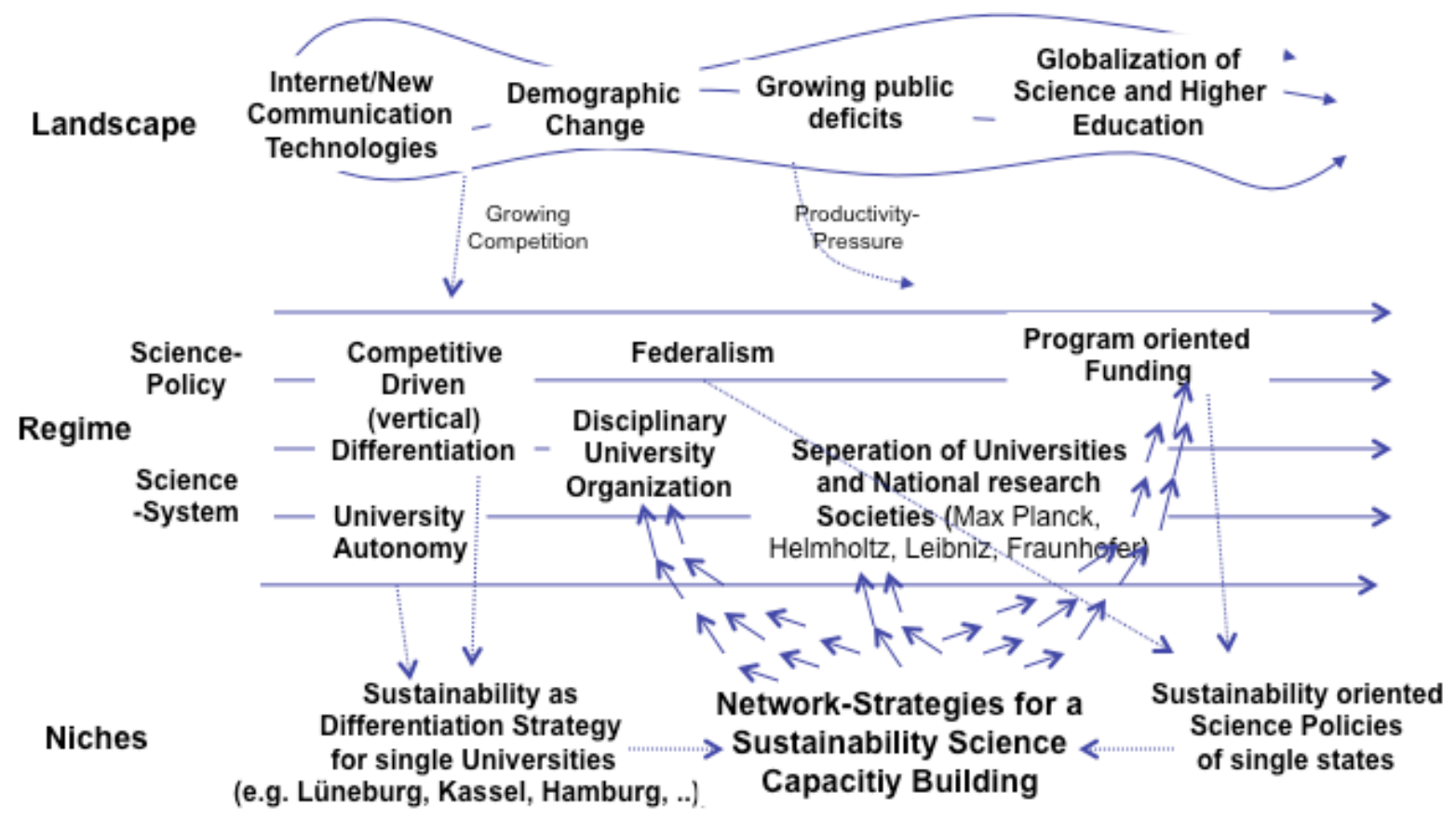

Fig. 1: Landscape, Regime and Niches in the German Science System

The current science system has developed historically over long periods of time. The interweaving of the state bureaucracy and academia, reputation and quality management systems based on grading and ranking systems, the importance of publications and a marketlike structure of the science system are all features that are today firmly embedded in the institutional structure of the science system - but have their origins in developments that date back to the early modern era beginning in the $18^{\text {th }}$ century (for a historic overview see Clark, 2006).

To analyze how the science regime interacts with landscape pressures and niche developments, it is helpful to differentiate between two types of sub-regimes: science-policy structures on the one hand, and the the internal institutional settings on the other hand: (1) The science policy structure is characterized by the European and national research policies, the state legislation ("Landeshochschulgesetze") and by funding strategies of science ministries. (2) The internal institutional settings consist of the organizational structure of the national science system (i.e. e.g. the division of university and non-university research), disciplinary reputation mechanisms, national and international scientific networks, career pathways within the science system as well as the degree of autonomy of universities within the system.

There are multifold inter-linkages between the two sub-regimes, e.g. program oriented funding strategies influencing the strategies of universities and research institutes (Geuna, 1999; Geuna and Martin, 2003; Rolfe, 2003).

The German science policy resumed the increased competitive pressure by pushing a stronger vertical integration of the German university system (e.g. by initiating the national excellence initiative (Kehm and Pasternack, 2008), by replacing basic funding by contractual and program funding (Horstmann, 2010). A specific German parameter is the strengthening of the 
state ("Länder")-level in the context of the reform of the federal system in 2006 (DFG, 2006), which gave more influence to science policy at the state level.

The internal institutional settings are characterized by increasing university autonomy over the last ten years, a still very disciplinary university organization and the weakened separation of university and non-university research (organized in the big national science organizations of the Max-Planck-, the Helmholtz-, the Leibniz- and the Fraunhofer society as well as in independent research institutes). Especially the excellence initiative has forced new cooperation between universities and non-university research institutes. And it has forced a focus on more disciplinary or weak interdisciplinary strategies to build the kind of excellence clusters that were demanded by the initiative.

When analyzing the potential for a science system transition towards transdisciplinary sustainability research, it becomes obvious that the current science regime would have to undergo substantial change to accommodate this new type of research more broadly. It has been shown that the science system is characterized by a stable regime that includes a specific institutional architecture and common principles governing the production of knowledge. However, as exemplified by various reforms of the higher education system, the regime is aware of moderate landscape pressures, such as globalization, demographic change etc., and adopts innovations, in order to adapt to these pressures and being able to persist. These reforms rarely cause radical change, because they are intended to stabilize the existing regime under changing circumstances and, thus, eventually lead to institutional traditions being upheld and strengthened (Miller et al., 2011). In addition, considering these regime dynamics, no inevitable developments concerning a sustainability science can be identified. Changes within the regime (competitive based university governance, strengthened state level, program funding orientation) so far are not pushing transdisciplinary sustainability research. In fact, the re-orientation towards disciplinary foci and a more traditional understanding of 'academic excellence' is even contradictory to transdisciplinary approaches.

Nonetheless, the fact that landscape pressures and the need to react to new challenges are recognized can, in general, present windows of opportunity for substantial change. The observed developments at the regime level provide strategic opportunities for different kinds of niche activities. Specific niche strategies aiming at the diffusion of transdisciplinary sustainability research will be analyzed in the following section.

\section{The potential for a transition towards "transdisciplinary sustainability research" in the German science system - The role of niche strategies}

The concept of transition pathways serves as a heuristic framework guiding the development of successful niche strategies. Ideal type transition pathways have been developed based on case studies of actual transitions that extended over several decades and, thus, cannot be understood as a means for forecasting the future course of a current transition. However, they do indeed provide a structured approach for better understanding underlying mechanisms in complex transitions. It is in this way that the pathways outlined above help to understand the structure and dynamics of the science system from a transition perspective. From this point of departure, the aim is to develop possible niche strategies aiming at future transitions that transcend the boundaries of purely descriptive pathways observed in retrospect.

Following the analysis of the science regime as well as relevant landscape factors, the focus will now shift to various niche developments which play an important role in triggering 
regime change. Different kinds of niche actors are of relevance, such as universities, research institutes and state governments.

\subsection{University niche strategies}

Single Universities can establish fruitful environments for transdisciplinary research by creating interdisciplinary centers and graduate schools, new study programs, appointments of interdisciplinary professorships. Hereby they are creating "islands" of transdisciplinary research. This can be a successful differentiation strategy to stay or become attractive for sustainability researchers and a student population that is seeking convincing study programs in the field of sustainability.

Some mid-sized German universities have chosen such an option to develop a sustainability profile over the last years (Schneidewind, 2009). The most prominent examples are the universities of Lüneburg, Kassel and Oldenburg. They created university-wide sustainability centers and graduate schools, raised new interdisciplinary professorships and initiated new sustainability study programs.

Choosing this strategy, the universities relied on existing regime developments like the enlarged university autonomy and a growing pressure for differentiation, in order to push their sustainability-oriented strategies. A recent example for such an approach is the "excellence strategy" of the University of Hamburg, one of the biggest German universities. The university failed to succeed in the first phase of the German excellence initiative (in 2006/2007) in being chosen as one of the German elite universities. In the second round of the initiative (the selection process started at the end of 2010 and will be finished in 2012) the new president of the University of Hamburg made a comprehensive sustainability strategy the core of Hamburg's application. Here the regime-typical excellence initiative provided the basis for pushing a university-wide sustainability strategy - even if the university eventually had not been chosen by the selection committee in March 2011.

\subsection{Research institutes/science-society-strategies}

Beside universities, non-university sustainability research institutes are a second group of relevant actors in practicing a transdisciplinary sustainability orientation within the science system. Several of such institutes exist in Germany - the biggest ones are the Umweltforschungszentrum (UFZ) in Leipzig, the Potsdam Institute for Climate Research (PIK), Fraunhofer Institutes like the ISI, the Fraunhofer Umsicht, the Wuppertal Institute for Climate, Environment and Energy and the Öko-Institute in Freiburg.

Despite doing a large part of the sustainability-oriented research carried out in Germany, the single institutes were very long not in a position to influence the German science system regime in such a way as to generally foster this type of research. Part of the explanation is that relevant elements of science system reproduction can only be realized within universities: granting Ph.D.-theses and offering professorial careers.

Recently however, the potential for the institutes' influence on the regime has increased due to two parallel developments: (1) the closer institutional cooperation of universities and other research institutes fostered by the excellence initiative, (2) sustainability initiatives and network building by various research associations and by groups of institutes.

The closer links between universities and non-university research institutes have only in a few cases been used to strengthen sustainability research: the institutional cooperation of the 
university of Kassel with the Umweltforschungszentrum Leipzig and the Wuppertal Institute is one example for this. None of the institutionalized types of cooperation in the context of the excellence initiative had a sustainability focus.

More dynamic developments could be observed in the network building of different sustainability research institutes:

A specific role for this development is played by the free ecological institutes that were founded from the end of the seventies onwards: the Öko-Institut, the Institute for Ecology and Economy (IÖW), the Institute for socio ecological research (ISOE), the IFEU, the Wuppertal Institute. They were founded in order to improve the science-policy link in dealing with ecological challenges, they complemented normal science research and they have incorporated many elements of a transdisciplinary research for more than 20 years now:

- Their research was always problem-oriented and defined scientific questions starting from concrete societal challenges,

- the research is closely defined together with actors in politics, business, environmental organizations,

- the research is mainly carried out in interdisciplinary teams.

The work of the free ecological research institutes very early fulfilled nearly all the criteria of transdisciplinary research. The support by specific research programs, for instance on"socioecological research" (SÖF) launched in 2000 helped to further improve the methodological standards of a transdisciplinary sustainability research and to form new scientific careers of transdisciplinary-oriented professorial candidates. This had an impact on the further establishment of this kind of research in the existing science system regimes. Nevertheless the idea -that came up at the end of the 1990ies- of creating a specific national research association (the so called "Green list") of the free ecological institutes to provide them with a better core funding failed.

Apart from the free institutes at least one of the national research organizations started a sustainability initiative: It was undertaken in 2010 by the Fraunhofer association: the board of the Fraunhofer association started a "sustainability network" of 18 Fraunhofer institutes and re-inforced the already existing sustainability cooperation of the 18 institutes by investing more than one million Euro in a strategic project to push the Fraunhofer focus on sustainability research.

The other national research organizations are engaged in sustainability research in many regards. So the Potsdam Institute for Climate Research is one of the approximately 90 Leibniz institutes, the Umweltforschungszentrum Leipzig is one of the 16 Helmholtz research centers. But none of these two associations has pushed sustainability research in such a strategic way on the overall organizational level as Fraunhofer.

\subsection{Niche coalitions/institutional coalitions and subject coalitions}

In spite of the university strategies and the activities of non-university research institutes no real pressure has been put on the science system regime yet. All these institutions have used existing regime factors like the differentiation opportunities and the improved program funding for sustainability research to improve their status within the system - however, without causing fundamental changes within the system as such.

In order to introduce substantial changes in the science system, a critical mass of cooperating institutions is lacking. Stronger niche coalitions are necessary to put more pressure on the 
regime. The crucial elements of niche strategies employed by such coalitions can already be identified:

As a first type of such coalitions strategies, coalitions of several universities and sustainability research institutes can have a relevant influence especially on the internal institutional structures of the science regime: They can foster joint capacity building in the form of: improved methodological standards for transdisciplinary research, the creation of refereed transdisciplinary journals, and, the constitution of joint graduate schools or institutes of advanced sustainability studies.

Only a critical mass of several universities guarantees career paths in the science system for young scientists that have been trained beyond classical disciplinary boundaries.

One of these coalitions is the "NaWis-Runde" (Sustainability Science Network) that was founded in the beginning of 2011 by the Universities of Kassel and Lüneburg, which both have developed sustainability profiles within their research and education activities, and the Wuppertal Institute as one of the leading sustainability research institutes in Germany. In 2012, the Institute for Advanced Sustainability Studies (IASS) in Potsdam joined the network. The "NaWis-Runde" serves as the German co-editor of the refereed transdisciplinary journal GAIA. The institutions establish joint research programs and graduate schools as well as joint professorships. An important characteristic of the network is the fact that the three founding institutions are located in different (large) German states: North-Rhine Westphalia (Wuppertal Institute), Lower Saxony (university of Lüneburg) and Hesse (university of Kassel), which also potentially gives them the opportunity to influence science policy structures.

Another example is the Helmholtz Alliance ENERGY-TRANS. This alliance brings together universities and non-university research institutes in a comprehensive 5-year project. An interdisciplinary research program on a sustainable energy transition in Germany is carried out by a coalition of the Karlsruhe Institute of Technology, different Helmholtz centres, the universities of Stuttgart and Magdeburg and the Centre for European Economic Research in Mannheim.

A second type of strategy that is of relevance relies on the incorporation of cooperation strategies within the excellence initiative. The University of Hamburg has chosen such an approach. Part of its institutional strategy within the excellence initiative application has been the focus on a network of northern German and European universities. Hamburg wants to position itself as a hub of sustainability research and teaching, that brings together a regional network of other universities having focal areas of sustainability research and teaching in their own institutions. This presents an alternative type of university coalitions, where the participating universities do not necessarily focus exclusively on a sustainability profile for their individual university as a whole. This may also become an effective diffusion strategy for sustainability-oriented research: various sustainability hubs spreading out subject-related and methodological sustainability science expertise into the whole system.

A third type of niche coalition is centred around the alliance of different subjects that are characterized by a high degree of transdisciplinary research: Apart from sustainability research this applies for gender research, health science or for intercultural studies (see e.g. the spectrum of the transdisciplinary field in Hirsch-Hadorn, 2008). Here it is possible to form coalitions within and between universities to create common methodological ground and an enhanced awareness for transdisciplinary career paths in different disciplines. 


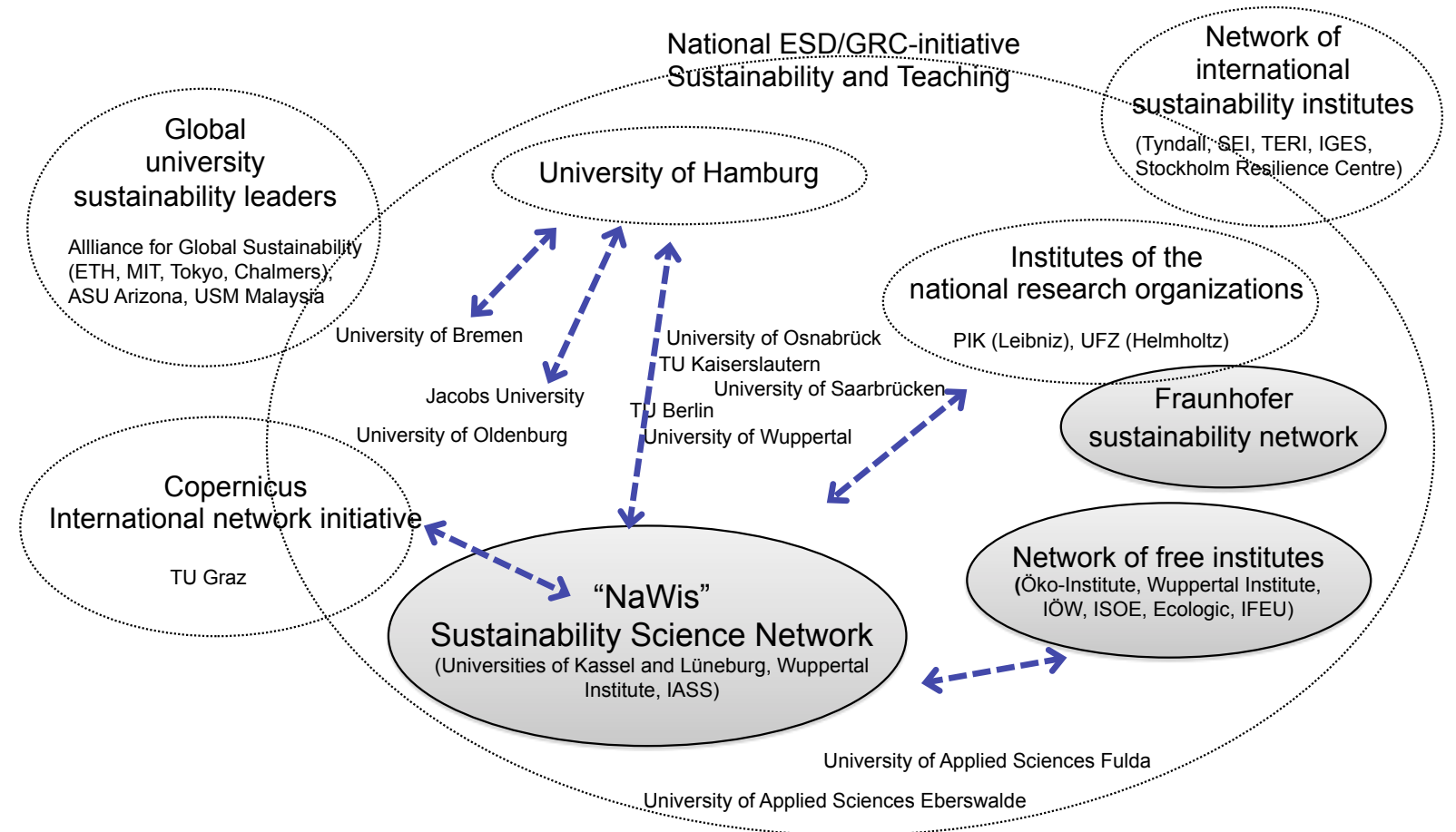

Fig. 2: Map of national niche-strategies and coalitions for pushing sustainability science

\subsection{Linking the national with international regimes}

So far only national niche coalitions have been described. Their nationally based activities could be strengthened by linking them with efforts in the context of international science systems. Due to the international organization of the inner science regime reputational and institutional relevance of such international activities can be helpful in supporting changes within the national science policy regime. In the field of transdisciplinary sustainability research several international initiatives exist: the international science programs of the Earth System Science Partnership ESSP, the European Sustainability Science Group (ESSG), or international networks concerned with transdisciplinary research like the TD-net or the Sustainability Transitions Research Network (STRN).

Figure 2 provides an overview of the existing niche coalitions within the German science system.

\subsection{An underestimated actor: German state governments}

An underestimated "niche actor" are state governments in Germany. Because of the strong federalism they possess a high influence on the German science policy (Edler and Kuhlmann, 2008). By using their program and contractual funding power they influence future strategies of the universities in the individual German states. Governments have not really used this influence to foster the diffusion of transdisciplinary research within the science system. This is astonishing in so far as many states have established ambitious state climate and sustainability strategies.

Niche strategies of single states could help to stabilize the strategies of sustainability-oriented universities, research institutions and their networks. In turn, these institutions could be a supporting factor for state sustainability strategies. 
Furthermore, coalitions of different states could be very effective especially in the context of the German federal system.

\section{Discussion and conclusion}

In order to analyze the role of these emerging niche developments in the context of a potential transition towards transdisciplinary sustainability research, recourse is taken to the concepts of the transformation and reconfiguration pathway.

First, these pathways describe a specific multi-level system configuration that can be compared to the science system and which helps to understand its basic structure and dynamics from a general transition perspective. For instance, as in these ideal type pathways, the science system regime is relatively stable and there is moderate landscape pressure. Another similarity in patterns and mechanisms is the way a dynamic emerges, where niche actors utilize landscape pressure, opportunities are presented by limited regime adaptations, and change begins to occur in a step-by-step manner, without major crises induced by landscape factors. For instance, it has been shown how universities, along the lines of the competition- and differentiation-oriented regime structures, strategically engaged in 'green' profile building. Similarly, non-universityresearch institutes utilized new possibilities to cooperate with each other and with universities in the framework of the German excellence initiative, in order to establish alternative career paths as a means of fostering and establishing forms of transdisciplinary sustainability research within the established system of academic education. Furthermore, it seems that some niche actors have found ways of accelerating the dynamics needed for a transition towards transdisciplinary sustainability research and the respective regime changes. Coalition building still relies on utilizing existing regime dynamics - as observed in individual activities - but specifically focuses on reaching a critical mass of change agents, which might accelerate the little steps towards more visible, fundamental changes.

Second, the way transformation and reconfiguration pathways have played out in past cases inspires ideas about possible future pathways of a science system transition - without claiming to provide an accurate forecast of fixed trajectories at any point in time. Developing a vision of a possible transition pathway, while at the same time having clearly delineated current system characteristics, allows for meaningful niche strategy development. In our case, a possible science system transition pathway could in the beginning look very much like the transformation and reconfiguration pathways, where a stable regime increasingly realizes the need to adapt to moderately changing circumstances. Therefore, innovations are adopted as a means to preserve the current regime. In the reconfiguration pathway for instance, a number of small-scale innovations that were not initially opposed to current regime structures, more or less accidentally became the starting point for a major reconfiguration, triggered by learning processes within the regime and by niche activities of industrial engineers (Geels, 2006). With regard to the science system, a strategic transition outlook would build on what can be learned from these developments, but proceed from a different starting point. In this case, niche actors would from the beginning aim at substantial change and act strategically regarding the long term. A niche strategy for a science system transition would rely on niche actors who utilize current system dynamics for their purpose of fostering the development of transdisciplinary sustainability research and the necessary institutional changes. Niche actors could build on the regime actors' efforts to adjust to landscape pressure as an opportunity to introduce incremental innovations that in the long run aim at fundamental change. 
In order to accelerate this transition, which is still in a predevelopment phase, suggestions have been made, which may support the niche strategies by universities and research institutes already taking shape. Based on insights about the German science system regime - especially the international orientation of the inner science regime and the role of federal states within the science policy regime - the emerging niches would profit from coordination efforts with the European level on the one hand, and with the German federal states and their political sustainability activities on the other hand.

In conclusion, it has been shown that the multi-level perspective and general patterns identified in various transition pathways are helpful to understand changes in the science system in its multilevel-interaction. It delivers a framework to better understand patterns that are relevant in the context of vital challenges like a stronger focus on transdisciplinary sustainability research and a strengthening of the science-policy interface within an existing national science system.

The case of the German science system has shown that the existing niche strategies are not sufficient to put substantial change pressure on the existing regime. Only coalitions of niche actors and activities will be able to increase the pressure on the regime - especially when interlinkages with science and sustainability policies on the federal, the state and the European level can be utilized.

This paper presents a first attempt to apply a multi-level perspective on transitions to a national science system. The conclusions stay inevitably speculative. To validate the findings, different kinds of future research designs are necessary: Qualitative process studies are needed that investigate the success or failure of niche coalitions and their strategies. In how far do these coalition strategies substantially affect the science regime in the long run? Furthermore, comparative international studies could shed light on the different ways of incorporating sustainability science in national science systems.

From a science policy perspective it is worthwhile - especially when considering the future development of the growing sustainability transitions research community - to further focus on the science system itself as an important sector for applying a transition research framework. 


\section{References}

Bergmann, M., Jahn, T., Knobloch, T., Krohn, W., Pohl, C., Schramm, E., 2010. Methoden transdisziplinärer Forschung: Ein Überblick mit Anwendungsbeispielen, Campus Verlag, Frankfurt a.M..

CASS (Konferenz der Schweizerischen Wissenschaftlichen Akademien), ProClim- (Forum für Klima und Global Change - Schweizerische Akademie der Naturwissenschaften), Forschung zu Nachhaltigkeit und Globalem Wandel: Wissenschaftspolitische Visionen der Schweizer Forschenden, ProClim, Bern, 1997.

Clark, W., 2006. Academic Charisma and the Origins of the Research University, The University of Chicago Press, Chicago.

Clark, C. C., Dickson, M. D., 2003. Sustainability science: The emerging research program, Proc. Natl. Acad. Sci. 100, 8059-8061.

DFG (Deutsche Forschungsgemeinschaft/German Research Foundation), 2006. The Impact of the Federalism Reform on Science and Research, Bonn. Retrieved March 2011 from the World Wide Web: http://www.dfg.de/en/research_funding/legal_conditions/federalism_reform/index.html ).

Edler, S., Kuhlmann, S., 2008. Coordination within fragmentation: Governance in knowledge policy in the German federal system, Sci. and Public Policy 35, 265-276.

Geels, F. W., Schot, J., 2010. The Dynamics of Transitions. A Socio-Technical Perspective, in: Grin, J., Rotmans, J., Schot, J. (Eds.), Transitions to Sustainable Development. New Directions in the Study of Long Term Transformative Change, Routledge, London, pp. 11105.

Geels, F. W., 2006. Major system change through stepwise reconfiguration: A multi-level analysis of the transformation of American factory production (1850-1930), Technol. in Soc. $28,445-476$.

Geuna, A., Martin, B. R., 2003. University Research Evaluation and Funding. An International Comparison, Minerva 41, 277-304.

Geuna, A., 1999. The Economics of Knowledge Production: Funding and the Structure of University Research, Edward Elgar, Northampton.

Gibbons, M., Limoges, C., Nowotny, H., Schwartzman, S., Scott, P., Trow, M., 1994. The new production of knowledge. The dynamics of science and research in contemporary societies, Sage, London.

Grin, J., Rotmans, J., Schot, J., 2010. Transitions to Sustainable Development. New Directions in the Study of Long Term Transformative Change, Routledge, London.

Grin, J., 2010. Understanding Transitions from a Governance Perspective, in: Grin, J., Rotmans, J., Schot, J. (Eds.), Transitions to Sustainable Development. New Directions in the Study of Long Term Transformative Change, Routledge, London, pp. 223-339. 
Harley, S., Lee, F. S., 1997. Research Selectivity, Managerialism, and the Academic Labor Process: The Future of Nonmainstream Economics in U.K. Universities, Hum. Relat. 50, 1427-1460.

Hirsch-Hadorn, G., 2008. Handbook of Transdisciplinary Research, Springer, Heidelberg.

Horstmann, A., 2010. Steuerung durch Programmförderung, Forschung. Politik - Strategie Management. 3, 2-7.

Jäger, J., 2011. Risks and Opportunities for Sustainability Science in Europe, in: Jäger, C. C:, Tabara, J. D., Jäger, J. (Eds.), European Research on Sustainable Development. Volume 1: Transformative Science Approaches for Sustainability, Springer, Heidelberg.

Kehm, B., Pasternack, P., 2008. The German 'Excellence Initiative' and Its Role in Restructuring the National Higher Education Landscape, in: Palfreyman, D., Tapper, T. (Eds.), Structuring Mass Higher Education: The Role of Elite Institutions, Routledge, London, pp. 113-127.

Kemp, R., Marten, P., 2007. Sustainable development: how to manage something that is subjective and never can be achieved? Sustainability: Sci. Pract. Policy. 3, 5-14.

Kemp, R., Loorbach, D., 2006. Transition management: a reflexive governance approach, in: Voss, J.-P., Bauknecht, D., Kemp, R. (Eds.), Reflexive Governance for Sustainable Development, Edward Elgar, Cheltenham, pp. 104-130.

Komiyama, H., Takeuchi, K., 2006. Sustainability science: building a new discipline. Sust. Sci. 1, 1-6.

Meadowcroft, J., 2009. What about the politics? Sustainable development, transition management, and long term energy transitions, Policy Sci. 42, 323-340.

Miller, T. R., Munoz-Erickson, T., Redman, C. L., 2011. Transforming knowledge for sustainability: towards adaptive academic institutions, International Journal of Sustainability in Higher Education 12, 177-192.

Nowotny, H., Scott, P., Gibbons, M., 2001. Re-Thinking Science. Knowledge and the Public in an Age of Uncertainty, Blackwell Publishers Ltd., Oxford.

Pohl, C., Hirsch Hadorn, G., 2007. Principles for Designing Transdisciplinary Research: Proposed by the Swiss Academies of Arts and Sciences, oekom Verlag, München.

Rolfe, H., 2003. University Strategy in an Age of Uncertainty: The Effect of Higher Education Funding on Old and New Universities, High. Educ. Q. 57, 24-47.

Rotmans, J., Loorbach, D., 2010. Towards a Better Understanding of Transitions and Their Governance. A Systemic and Reflexive Approach, in: Grin, J., Rotmans, J., Schot, J., (Eds.), Transitions to Sustainable Development. New Directions in the Study of Long Term Transformative Change, Routledge, London, pp. 105-223. 
Rotmans, J., Kemp, R., van Asselt, M., 2001. More evolution than revolution: transition management in public policy; Foresight. The Journal of future studies, strategic thinking and policy $3,15-31$.

Scholz, R. W., 2011. Environmental Literacy in Science and Society. From Knowledge to Decisions, Cambridge University Press, New York.

Shove, E., Walker, G., 2007. CAUTION! Transitions ahead: politics, practice and sustainable transition management, Environ. and Plan. A 39, 763-770.

Schneidewind, U., 2009. Nachhaltige Wissenschaft. Plädoyer für einen Klimawandel im deutschen Wissenschafts- und Hochschulsystem, Metropolis Verlag, Marburg.

Stephens, J. C., Graham, A. C., 2010. Toward an empirical research agenda for sustainability in higher education: Exploring the transition management framework. J. of Clean. Prod. 18, 611-618.

van den Bergh, J. C. J. M., Truffer, B., Kallis, G., 2011. Environmental innovation and societal transitions: introduction and overview, Environmental Innovation and Societal Transitions 1, 1-23.

Voß, J.-P., Kemp, R., 2005. Reflexive Governance for Sustainable Development Incorporating feedback in social problem solving, Paper for ESEE Conference June 14-17, 2005 in Lisbon, Special session on Transition management, Retrieved July 2010 from the World Wide Web: http://kemp.unu-merit.nl/pdf/VossKemp\%20Reflexive\%20Governance\%20for\%20ESEE\%202005.pdf

Waas, T., Verbruggen, A., Wright, T., 2010. University research for sustainable development: definition and characteristics explored, J. of Clean. Prod. 18, 629-636.

Wagner, G., 2007. Does excellence matter? Eine wissenschaftssoziologische Perspektive, Soziologie 36, 7-20.

Wiek, A., Farioli, F., Fukushi, K., Yarime, M., 2012. Sustainability science: bridging the gap between science and society, Sust. Sci. 7, 1-4.

Yarime, M., Trencher, G.,Mino, T., Scholz, R. W., Olsson, L., 2012. Establishing sustainability in higher education institutions: towards an integration of academic development, institutionalization, and stakeholder collaborations, Sust. Sci. 7, 101-113.

Zierhofer, W., Burger, P., 2007. Disentangling Transdisciplinarity: An Analysis of Knowledge Integration in Problem-Oriented Research, Sci. Stud. 20, 51-74. 